DOI: $10.15503 /$ jecs20151.101.107

\title{
DEPRESSION AS AN ESCAPE FROM BURDEN OF LIFE
}

\author{
Magda Bartoskova \\ Charles University in Prague, Department of Psychology at Faculty of Education, \\ Myslikova 7, 110 00, Prague 1, Czech Republic \\ E-mail address: bartoskova.magda@gmail.com
}

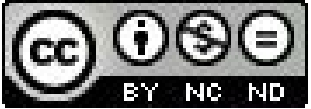

\begin{abstract}
This study aims to explore the inner world of people suffering from depressive disorder. Four people hospitalized in Prague Psychiatric Centre were interviewed. Method of Grounded Theory and discursive analysis revealed a specific way of depressive thinking and experiencing the self and the outer world. Depressive individuals manifest deficit in introspection. They do not perceive themselves as the authors of their lives and they show a tendency to look for external, estranged meanings of life. Combination of these attributes was found to be possible psychological cause leading towards the outburst of depressive disorder. Significant similarities were found between research results and C.G. Jung's understanding of depressed people, which he describes through energetic model of libido.

Keywords: depression, introspection, authorship of life, external life meaning, qualitative research, C.G. Jung
\end{abstract}

\section{INTRODUCTION}

Do people suffering from depression show common features in the way of thinking? How does the inner world of people suffering from depression look like? How do they experience themselves and the world around them?

When searching for answers, we can find a specific vulnerability described by many authors as one of the possible psychological causes of depression (Praško, 2008; Raboch, 2012; Rahn, 2000). Jan Praško (2008) talks about a disposition, which is one of the basic prerequisites of the depressive disorder. According to him this disposition is formed by excessive sensitivity and increased vulnerability. According to Jiří Raboch (2012), a risk of depression is higher for some types of personalities or character traits. More specifically it is for instance rigidity, dominance, dependency or obsession. Such individuals have typically higher sense of order, tendency to higher performance and furthermore, they are usually dependent on others. Ewald Rahn (2000) describes a model of vulnerability where cognitive abilities of a person seem to be very significant for the outburst of the depressive disorder. Type of judgement, evaluation and meaning creation process form a specific cognitive binding structure. The structure is a basis of vulnerability towards depression.

We can understand this vulnerability as a predisposition that is manifested in a way a person thinks and structures the experience. In literature we can find evidence for common cognitive features of depressive individuals. 
The aim of this study was an attempt to understand the "inner world" of people suffering from depression. The qualitative research was focused on getting closer to perceiving and experiencing the depressive disorder by depressive individuals themselves. As appropriate way to do so turned out to be an investigation of their life stories. The structure of thinking and experiencing can be looked into pursuant the life story shown. Based on this data we can create an idea of which factors may be crucial during the development of depression. Results of the research are captured as a model describing reluctance to pursue introspection, which leads to deficit of authorship in life. Following this, the individual tends to desire and look for meanings of life that are substitution and external to him. "Real" meanings of life could be pursued only provided that one knows himself, that one has a developed introspection ability. The external meaning of life does not have a long lasting. Its attractiveness decreases and soon another replaces it. The best before date of any other new external life meaning is getting shorter and shorter. Eventually the time comes that no other external life meaning can be found to replace the vast space. At this particular moment the depressive episode attacks in its full force.

In addition, Carl Gustav Jung's ideas about depression and its outburst are compared with the findings. C. G. Jung's model of depleted libido was found to have a strong correspondence with the research results.

\section{METHODS}

The aim of the study was not to verify hypotheses, but an attempt to understand the essence of the explored phenomenon. It was crucial not to reduce the research topic to some pre-defined area. The focus in this study was on subjective perceiving the reality of the depressed individuals themselves. Therefore a qualitative research was chosen drawing on the approach of Grounded theory by Anselm Strauss and Juliet Corbin (1999).

Participants. Four participating individuals were hospitalized for depression in Prague Psychiatric Centre. The inclusion criteria were: actual hospitalization for depression and willingness to share their experience. The exact diagnosis was not an inclusion criterion because of the similarities within the clinical picture of different types of depression.

The research group differed in many aspects: Chosen respondents were of different: age, sex, social background, level of education, marital status, experience with alcohol and drug abuse.

Participant no. 1: woman, 37 years, repeated major depressive episode.

Participant no. 2: man, 59 years, repeated major depressive episode.

Participant no. 3: woman, 48 years, moderately severe depressive episode - first.

Participant no. 4: woman, 17 years, repeated major depressive episode.

Data collection. Data were collected through a narrative interview combined with elements of a problem-oriented interview (Hendl, 2005). The interviews were conducted in a private room at a psychiatric unit of the clinic. At initiation of every 
interview, following instruction was given: "I would like to ask you to tell me the story of your life. You may begin at whichever point you like. I am also interested about the beginning of the depression, how do you understand it in the context of your life and what does it mean to you". Each autobiographical interview was about 90 minutes long. The participants pursued their life stories. After finishing their narration, questions were asked. Open questions naturally followed topics which participants already started.

Data analysis. The Grounded Theory method by A. Strauss and J. Corbin (1999) combined with discursive analysis was used in this study. Spoken words in narratives were literally transcribed and analysed. The Grounded Theory method consists of three level coding. The results of the analysis are depicted in created categories and a model.

\section{RESULTS}

In this part the most significant categories will be presented as well as the created model. The categories reflect how do the respondents describe their experiencing, sense of their lives, relations to others, way of their behaviour and strategies they usually use to solve problems. The model then shows specific interconnections between the categories.

\section{CATEGORIES}

Deficit of introspection. Depressive individuals were not able to describe their feelings. Description of their inner states was usually simple, very often accomplished even with a single word. It seemed as if the participants were not even counsicous of their feelings. It seemed as if they would rather concentrate the attention on physical symptoms. The physical symptoms are in a certain sense tangible and easier to grasp, but above all somehow "external" and independent on them. The cause of depression as well as the possible way out of it was seen in external, tangible world, in a change of environment. The ability of introspection was for the respondents during the depressive period largely unattainable.

Deficit of authorship. Participants spoke in a way, which implied that they are not in a control of their actions or feelings. The narrations gave the impression that it is necessary to act not pursuant their own will but pursuant coercion of circumstances the life has brought. The character of their behaviour was solely reactive. The respondents were not able to imagine a possibility of changing the current "order of things". Moreover their reactions to this "order" seemed to be the only possible ones. Problems or difficulties were most probably unbearable to them. On the grounds of this unbearableness they "decided" to assign the origin of their behaviour and their feelings to some outer power. The outer power was "the one" responsible for any occured situation or their psychological state.

Need for understanding and helpful other. The understanding other is helpful to the participants in areas they are not able to function independently, due to the deficit in introspection. When this special person fails to fulfil its function, the unfulfilled need of the participant leads towards an outburst of a depressive 
episode. Relationships with the understanding other may be considered as unbalanced. The reason dwells in the fact that the other is used to fulfil the needs, which depressive individuals are not able to fulfil independently. Depressive individuals act as if they rejected to understand themselves and to act on a behalf of themselves. In the other they look for a substitute of their subjectivity, probably because the subjectivity placed in their own psychological space would mean too great a burden.

Escape. The escape refers to a specific feature of participants' behaviour, which was used as a problem solving strategy. Respondents avoid trying to solve problems. The escape is very often connected with creating accidental, unpremeditated and reckless behavioural strategy. Category of escape illustrates a compensatory mechanism. Depressed individuals use this mechanism in accordance to deal with problems emerging in areas depicted in all presented categories.

External life meaning. External life meaning is in case of depressive individuals usually a target of the escape strategy. Depressed individuals decide to look for the meaning of life among external targets. The targets are not only external for their appurtenance to the "external world". They are external because they are not chosen based on conscious decision. The external life meanings serve as an overlap of unsatisfactory feeling of life or self. Character of objects which the depressed individuals decide to insert the meaning of life into was in none of the cases connected with their inner world. On the contrary the meaning of life they looked up to was a part of the "world outside" which should bring a sense into their lives. They never went for love, friendship, care for others because all of these goals require functioning relationships they were not able to establish. External meaning of life is an outcome of the escape strategy and it is directed towards the external meaning of life, because the inner meaning of life requires the ability of introspection, which the depressive people are not endowed with.

Depletion of external life meaning. With time the external life meanings lose their original attractiveness. Goals that were put on pedestal start to reveal negative aspects, which are of course inherent to every object. Depressive individuals are however able to deny this fact for some time. Confrontation with the ambivalence leads to a displacement of the negative aspects of the object. On the grounds of the displacement an idealistic form of these objects in the inner world of depressive person is created. Such tendency becomes a cause of an inability to establish "fully functional" relationship. Depressive individuals do not form their relation to the "real objects" but to the objects that are dissimilar to the reality. An orientation to "non-real" objects generates a discrepancy with the "real one". When the real object disappears from the respondent's life the discrepancy culminates. A confrontation of the unreal object with the absence of the object in reality is inevitable. An unbearable depletion of the external life meaning follows. The depressed individual has a possibility to clamp to some other external life meaning. When this happens the compensatory mechanism gets becomes a "closed loop". After the depletion of external life meaning a new external life meaning is looked for in order to fill the vast space. 


\section{MODEL}

The most significant phenomenon is the deficit of introspection. It is the starting point of a journey towards depression. Reluctance and inability of knowing himself influences all aspects of depressive individual's life as well as a formulation of his life story.

Insufficient knowledge of one's self causes an ignorance of possible alternatives. Standing in front of a narrowed choice a person is not willing to take a clear stand and assume a responsibility for his decisions. The unbearable responsibility is put on a person, which would make the decision instead of him. Giving up the responsibility leads to losing a possibility to determine the direction of one's life, to losing the authorship of life.

Deficit of introspection causes the escape towards external life meaning. Knowing the real one would require the ability of introspection. Favouritism towards the escape strategy leads to loosing the possibility of recovering the functional behavioural strategies. The goal of the escape is not correspondent to the structure of personality. Due to unreflected part of personality it is external to the depressive person. The object of the goal does not match the object in reality. While establishing a relationship the unsuitable components of the real object are missing in the mental representation of the depressive individual. While confronting the mental representation with the real object a depletion of the external meaning follows.

Eventually the depressive individual is not able to stay actively involved in life. Sooner or later a new external meaning is found. Its nature is even farther from the real necessities of the depressive person. Therefore the depletion comes even faster. When there is no other external life meaning found, the loop of compensatory mechanism fails and the outburst of depressive episode comes.

\section{DISCUSSION}

Findings in this study were that depressive individuals have a deficiency in the ability of introspection. Significant feature found was a need of a person fulfilling this deficiency instead of them, a person which would take over the responsibility they try to get rid of. The depressed individuals are therefore not the authors of their lives and they look for external life meanings, which are easily depleted. Similar model describing depression was found in work of C.G. Jung.

C. G. Jung describes the dynamics of depression through his model of libido. C.G. Jung's model and the study results concur in deficit of introspecion being an important feature at the inception of depression. Based on the insufficient knowing the self a non-adequate relationship to the object in the real world is created (Jung, 2001; 2004). Libido of every individual is fully attached to the object in reality. Every object contains ambivalent contents. Fear of revealing one's own imperfections (forced introspection) does not allow the depressive individual to reflect the ambivalence of the object. Unsuitable contents must be displaced to the unconsciousness together with the libido (Jung 1969; 2001).

C. G. Jung states that unsuitable aspects of the object towards which the goal of life is tied to are displaced into the unconscious. Part of libido formerly tied 
to the unsuitable aspects of the object is moved to the unconscious as well. The unconscious is therefore enriched by the libido's energy. Such energy generates pressure. The aim of the pressure is to compensate one-sided relation to the object (Jung, 2004; Steinberg, 1998).

One-sidedness is an inevitable consequence of displacing the unsuitable contents of the conscious to the unconscious (Jung 1969; 1999). Such "movements" are then responsible for a loss of an interest in the affairs of the outer reality, which is manifested as depression. "It is from these very losses that one-sidedness results, and this causes the standstill and consequent disorientation. In psychological terms, one-sidedness may lead to sudden loss of libido. All our previous activities become uninteresting, even senseless and the goals towards which we strove lose their value. What in one person is merely a passing mood may in other become a chronic condition" (Jung, 1933, p. 72).

The process in C. G. Jung's energetic model of the libido corresponds also with the findings regarding the depletion of the external life meaning due to the escape strategy. Trying to avoid the generated unconscious pressure, the depressive individual repeatedly uses the escape strategy. Such behaviour causes further displacement of the libido from the conscious to the unconscious. The more the pressure grows the more the depressive person escapes from it. Behaviour of many depressive individuals causes strengthening the mechanisms leading towards the depletion of external life meaning in spite of their evaluation of such behaviour as a possible way towards the desired state. The libido still held in consciousness is impoverished. Inevitable result of this strategy is a depletion of the libido in conscious, thus the outburst of depression.

To summarise briefly, according to the study findings, similarities in the way of thinking and behaving of depressive individuals were found. The respondents showed a low ability of introspection, which led to a need of an understanding and helping other who would take over this function. The depressive individuals were not authors of their lives. They tried to get rid of responsibility which proved to be one of the reasons why they chose the escape as a coping strategy for most of the problems they had. Usually they tried to escape finding something they could insert their life meaning into. Such life meanings were found external to their actual needs which was the reason why they did not have a long lasting. After series of depleted external life meanings and looking for new ones, the time came when there was no other satisfactory found. At this moment depression appeared in its full force. The results were found to be in correspondence with the C. G. Jung's ideas about depression, mainly about the presence of deficit in introspection and the depletion of external life meaning due to the escape strategy.

\section{REFERENCES}

Hendl, J. (2005). Kvalitativní výzkum: základní metody a aplikace [Qualitative Research: Fundamental Methods and Applications]. Praha: Portál.

Jung, C. G. (2001). Obraz člověka a obraz boha [Freud and Psychoanalysis]. Brno: Nakladatelství Tomáše Janečka. 
Jung, C. G. (1998). Osobnost a přenos [The Psychogenesis of Mental Disease]. Brno: Nakladatelství Tomáše Janečka.

Jung, C. G. (2004). Symbol a libido [Two Essays on Analytical Psychology]. Brno: Nakladatelství Tomáše Janečka.

Jung. C. G. (1969). The Structure and Dynamics of the Psyche. London: Routhledge.

Jung, C. G. (1933). Modern Man in Search of Soul. London: Kegan Paul, Trench, Trubner \& CO. LTD.

Praško, J. (2008). Deprese a jak ji zvládat [What Is Depression and How to Cope with It]. Praha: Portál.

Raboch, J. (2012). Psychiatrie [Psychiatry]. Praha: Karolinum.

Rahn, E. \& Mahnkompf, A. (2000). Psychiatrie. Učebnice pro studium a praxi [Psychiatry. The Text Book for Theory and Practice]. Praha: Grada Publishing.

Steinberg, W. (1989). Depression: A Discussion of Jung's ideas. Journal of Analytical Psychology, 34(4), pp. 339-352.

Strauss, A., Corbin, J. (1999). Základy kvalitativního výzkumu: postupy a techniky metody zakotvené teorie [Basics of Qualitative Research: Techniques and Procedures for Developing Grounded Theory]. Boskovice: Albert. 